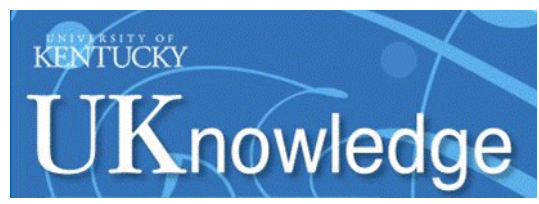

University of Kentucky

UKnowledge

\title{
Numerical Investigation of Pyrolysis Gas Blowing Pattern and Thermal Response using Orthotropic Charring Ablative Material
}

Haoyue Weng

University of Kentucky, kimomt@gmail.com

Alexandre Martin

University of Kentucky, alexandre.martin@uky.edu

Follow this and additional works at: https://uknowledge.uky.edu/me_facpub

Part of the Aerodynamics and Fluid Mechanics Commons, and the Computer Sciences Commons Right click to open a feedback form in a new tab to let us know how this document benefits you.

\section{Repository Citation}

Weng, Haoyue and Martin, Alexandre, "Numerical Investigation of Pyrolysis Gas Blowing Pattern and Thermal Response using Orthotropic Charring Ablative Material" (2014). Mechanical Engineering Faculty Publications. 2.

https://uknowledge.uky.edu/me_facpub/2

This Conference Proceeding is brought to you for free and open access by the Mechanical Engineering at UKnowledge. It has been accepted for inclusion in Mechanical Engineering Faculty Publications by an authorized administrator of UKnowledge. For more information, please contact UKnowledge@lsv.uky.edu. 


\title{
Numerical Investigation of Pyrolysis Gas Blowing Pattern and Thermal Response using Orthotropic Charring Ablative Material
}

\author{
Digital Object Identifier (DOI) \\ http://dx.doi.org/10.2514/6.2014-2121 \\ Notes/Citation Information \\ Published in the Proceedings of the 11th AIAA/ASME Joint Thermophysics and Heat Transfer \\ Conference, Paper 2014-2121, p. 1-13.
}

Copyright $\odot 2014$ by Haoyue Weng and Alexandre Martin.

The copyright holders have granted the permission for posting the article here. 


\title{
Numerical Investigation of Pyrolysis Gas Blowing Pattern and Thermal Response using Orthotropic Charring Ablative Material
}

\author{
Haoyue Weng* and Alexandre Martin ${ }^{\dagger}$ \\ University of Kentucky, Lexington, KY, 40506
}

\begin{abstract}
An orthotropic material model is implemented in a three-dimensional material response code, and numerically studied for charring ablative material. Model comparison is performed using an iso-Q sample geometry. The comparison is presented using pyrolysis gas streamlines and time series of temperature at selected virtual thermocouples. Results show that orthotropic permeability affects both pyrolysis gas flow and thermal response, but orthotropic thermal conductivity essentially changes the thermal performance of the material. The effect of orthotropic properties may have practical use such that the material performance can be manipulated by altering the angle of orthotropic orientation.
\end{abstract}

\section{Introduction}

I IGHT-WEIGHT charring ablators have become a popular material to use in Thermal Protection Systems $\mathcal{L}$ (TPS), for hypersonic atmospheric entry missions. ${ }^{1,2}$ Charring ablative materials are made of a fibrous non-pyrolyzing matrix (carbon, ceramic, etc.) impregnated with pyrolyzing material (phenolic, silicon resin). One of the features of these materials is to absorb the aerodynamic heat through the endothermic reaction of pyrolysis and ablation. ${ }^{3}$ Pyrolysis is the process in which the pyrolyzing polymer gradually carbonizes at high temperature, losing mass and generating pyrolysis gas. The other phenomenon, near surface ablation, occurs in a thin layer near the surface and refers to the mass removal of the char (composed of non-pyrolyzed and residual carbonized material) through oxidation, sublimation, and spallation.

Recently, Weng and Martin ${ }^{4}$ show that due to the high enthalpy carried by the pyrolysis gas, the gas flow behavior within a charring ablator is crucial to the inner thermal response of the material. In addition, since the gas is eventually blown into the chemical reacting boundary layer, ${ }^{5}$ correct modeling of the pyrolysis gas is also important to help determine the surface boundary conditions. The gas flow within the charring ablator is often modeled as porous media flow, where steady-state Darcy's law is usually assumed. ${ }^{6,7,8,9}$ For unsteady charring ablation problems, however, Ref. 4 shows that steady-state of Darcy's law is not necessarily valid for the whole geometry of small test articles used in arc-jet facilities. Hirata et. al. ${ }^{10}$ also proposed to use an unsteady version of Darcy's law, and they also identified a side wall blowing effect on arc-jet test samples. However, their material property model is quite simple, especially for the permeability of the material, which was assumed to be constant. Marschall and $\operatorname{Cox}^{11}$ show a great difference between virgin and char properties through experiments. In their work, the orthotropic behavior of charring ablative materials was also addressed. Specifically, ablative materials like PICA ${ }^{12}$ and SIRCA $^{13}$ have different permeabilities and thermal conductivities between the in-plane (IP) direction and the through-the-thickness (TTT) direction. This behavior is due to the orientation of carbon (or ceramic) fibers on a micro scale. ${ }^{14}$ However, literatures regarding the effect of orthotropic material properties are limited. This is perhaps due to the fact that investigation of orthotropic model requires at least a two-dimensional (2D) code, while most of the MR solvers are in one-dimensional (1D). ${ }^{15,16,17}$

Using the three-dimensional (3D) material response (MR) code developed in the present effort, the effects of orthotropic material properties are numerically studied. In particular, the difference between isotropic

\footnotetext{
* Graduate Research Assistant, Department of Mechanical Engineering, AIAA Student Member

$\dagger$ Assistant Professor, Department of Mechanical Engineering, Associate Faculty - Center for Computational Science, AIAA Senior Member
} 
and orthotropic model is investigated by looking at the thermal response and surface gas blowing pattern of a charring ablative material. The outcome of this work demonstrates the implemented orthotropic material model and its significance.

\section{Numerical Framework}

The 3D MR code developed in this work is Kentucky Aerodynamic and Thermal-response System (KATS). ${ }^{18,19}$ It is a paralleled code that uses ParMETIS ${ }^{20}$ for domain decomposition and MPI for message passing. KATS is based on finite volume method. The general conservation form of equations can be written as:

$$
\frac{\partial \mathbf{Q}}{\partial t}+\nabla \cdot\left(\mathbf{F}-\mathbf{F}_{\mathbf{d}}\right)=\mathbf{S} .
$$

Using backward Euler method and spatial integration, the following linear system is thus solved for each control volume, at each time step:

$$
\left[\frac{V}{\Delta t} \frac{\partial \mathbf{Q}}{\partial \mathbf{P}}-\frac{\partial \mathbf{R H S}}{\partial \mathbf{P}}\right] \Delta \mathbf{P}=\mathbf{R H S},
$$

where $\mathbf{P}, \mathbf{Q}$, and $\mathbf{S}$ are vectors of primitive variables, conservative variables, and source terms, respectively. In this equation, RHS represents the right hand side of the linear system and is defined by:

$$
\mathbf{R H S} \equiv-\sum_{\text {faces }}\left(\mathbf{F}-\mathbf{F}_{\mathbf{d}}\right) \cdot \mathbf{n} A+\mathbf{S} V
$$

where $\mathbf{F}$ and $\mathbf{F}_{\mathbf{d}}$ are respectively the matrices of convective and diffusive flux. The numerical scheme used to calculate the convective flux is AUSM+-up (Advection Upstream Splitting Method). ${ }^{21}$ The first Jacobian matrix $\partial \mathbf{Q} / \partial \mathbf{P}$ in Eq. (2) is calculated analytically and the second Jacobian $\partial \mathbf{R H S} / \partial \mathbf{P}$ is obtained numerically via forward difference, where the perturbation to $\mathbf{P}$ is as small as the smallest positive floatingpoint number in double precision. The large sparse linear Eq. (2) is solved in the system at each time step, via PETSc library. ${ }^{22}$

\section{Proposed models}

The material response module in KATS solves for gaseous mass, solid mass, momentum and energy conservations. The governing equations, in the context of Eq. (1) and (2), can be represented by the following vectors and matrices:

$$
\begin{aligned}
& \mathbf{Q}=\left(\begin{array}{c}
\phi \rho_{g} \\
\rho_{s_{1}} \\
\rho_{s_{2}} \\
\rho_{s_{3}} \\
\phi \rho_{g} u \\
\phi \rho_{g} v \\
\phi \rho_{g} w \\
\phi E_{g}+E_{s}
\end{array}\right), \quad \mathbf{P}=\left(\begin{array}{c}
\phi \rho_{g} \\
\rho_{s_{1}} \\
\rho_{s_{2}} \\
\rho_{s_{3}} \\
u \\
v \\
w \\
T
\end{array}\right), \quad \mathbf{S}=\left(\begin{array}{c}
\dot{\omega}_{g} \\
\dot{\omega}_{s_{1}} \\
\dot{\omega}_{s_{2}} \\
\dot{\omega}_{s_{3}} \\
D_{x} \\
D_{y} \\
D_{z} \\
S_{D}
\end{array}\right), \\
& \mathbf{F}=\left(\begin{array}{ccc}
\phi \rho_{g} u & \phi \rho_{g} v & \phi \rho_{g} w \\
0 & 0 & 0 \\
0 & 0 & 0 \\
0 & 0 & 0 \\
\phi \rho_{g} u^{2}+p & \phi \rho_{g} v u & \phi \rho_{g} w u \\
\phi \rho_{g} u v & \phi \rho_{g} v^{2}+p & \phi \rho_{g} w v \\
\phi \rho_{g} u w & \phi \rho_{g} v w & \phi \rho_{g} w^{2}+p \\
\phi \rho_{g} u H & \phi \rho_{g} v H & \phi \rho_{g} w H
\end{array}\right), \quad \mathbf{F}_{\mathbf{d}}=\left(\begin{array}{c} 
\\
\\
\\
\\
\\
\mathbf{F}_{\text {conduction }}
\end{array}\right)
\end{aligned}
$$




\section{Pyrolysis gases model}

In this work, the pyrolysis gases are assumed to be in chemical equilibrium and are treated as a single gas species. The gas properties (e.g. viscosity, heat capacity) are obtained via equilibrium calculations.

\section{Solid decomposition model}

For solid species, a phenomenological three-components model is used for the charring ablative material. ${ }^{15}$ The ablating surface recession, however, is not modeled in this work. The total solid density is computed by

$$
\rho_{s}=\sum_{i=1}^{3} \Gamma_{i} \rho_{s_{i}}
$$

where $\Gamma_{i}$ is the volume fraction of species $i$ in the virgin composite. The intermediate properties are interpolated from virgin and char state, including porosity $\phi$, permeability $K$, thermal conductivity $k$, etc. The decomposition rate of each solid components is given by:

$$
\dot{\omega}_{s_{i}}=\frac{\partial \rho_{s_{i}}}{\partial t}=-A_{i} \rho_{v_{i}}\left(\frac{\rho_{s_{i}}-\rho_{c_{i}}}{\rho_{v_{i}}}\right)^{\psi_{i}} \exp \left(\frac{-E_{i}}{R T}\right), \quad T>T_{\text {react }_{i}}
$$

where subscript $v$ and $c$ are respectively for virgin and char state of the solid material. The solid decomposition and pyrolysis gas generation balance themselves, thus ensuring total mass conservation:

$$
\dot{\omega}_{g}=-\frac{\partial \rho_{s}}{\partial t}=-\sum_{i=1}^{3} \Gamma_{i} \dot{\omega}_{s_{i}}
$$

\section{Gas momentum model}

In this work, the gas transport is solved in a distinct momentum equation, which is a time dependent version of Darcy's law. ${ }^{23}$ The diffusive effect of porous media is treated as a source term in each direction of the momentum equation, that is $D_{x}, D_{y}$, and $D_{z}$, as depicted in Eq. (4). These terms, in general, can be calculated by solving the following linear equation:

$$
\left(\begin{array}{ccc}
K_{x x} & K_{x y} & K_{x z} \\
K_{y x} & K_{y y} & K_{y z} \\
K_{z x} & K_{z y} & K_{z z}
\end{array}\right)\left(\begin{array}{c}
D_{x} \\
D_{y} \\
D_{z}
\end{array}\right)=-\phi \mu\left(1+F_{o}\right)\left(\begin{array}{c}
u \\
v \\
w
\end{array}\right)
$$

where $F_{o}$ is Forcheimer number and the term $1+F_{o}$ accounts for high velocity effects on pore scale. The three-by-three matrix on the left hand side is a general anisotropic tensor of solid permeability. If the material is assumed to be orthotropic, such that the in-plane is the $x-y$ plane and the through-the-thickness direction is the $z$-direction, Eq. (9) can be greatly simplified:

$$
\begin{gathered}
\left(\begin{array}{ccc}
K_{I P} & & \\
& K_{I P} & \\
& & K_{T T T}
\end{array}\right)\left(\begin{array}{c}
D_{x} \\
D_{y} \\
D_{z}
\end{array}\right)=-\phi \mu\left(1+F_{o}\right)\left(\begin{array}{c}
u \\
v \\
w
\end{array}\right), \\
\Rightarrow D_{x}=-\frac{\phi \mu}{K_{I P}}(1+F o) u, \quad D_{y}=-\frac{\phi \mu}{K_{I P}}(1+F o) v, \quad D_{z}=-\frac{\phi \mu}{K_{T T T}}(1+F o) w .
\end{gathered}
$$

However, if the TTT direction is rotated by an angle $\theta$ (between TTT and $z$ direction), Eq. (10) becomes:

$$
\left(\begin{array}{ccc}
\cos \theta & -\sin \theta & 0 \\
\sin \theta & \cos \theta & 0 \\
0 & 0 & 1
\end{array}\right)\left(\begin{array}{ccc}
K_{I P} & & \\
& K_{I P} & \\
& & K_{T T T}
\end{array}\right)\left(\begin{array}{ccc}
\cos \theta & \sin \theta & 0 \\
-\sin \theta & \cos \theta & 0 \\
0 & 0 & 1
\end{array}\right)\left(\begin{array}{c}
D_{x} \\
D_{y} \\
D_{z}
\end{array}\right)=-\phi \mu\left(1+F_{o}\right)\left(\begin{array}{c}
u \\
v \\
w
\end{array}\right)
$$

The diffusive effect of porous medium flow in the energy equation is modeled as a source term:

$$
S_{D}=\left(\begin{array}{c}
D_{x} \\
D_{y} \\
D_{z}
\end{array}\right)\left(\begin{array}{lll}
u & v & w
\end{array}\right)=D_{x} u+D_{y} v+D_{z} w
$$




\section{Mixture energy model}

The mixture energy equation assumes the gas and solid are in thermal equilibrium. The conductive heat flux, as shown in $\mathbf{F}_{\mathbf{d}}$ of Eq. (5), is also given in a generic anisotropic fashion as following:

$$
\mathbf{F}_{\text {conduction }}=\left(\begin{array}{lll}
k_{x x} & k_{x y} & k_{x z} \\
k_{y x} & k_{y y} & k_{y z} \\
k_{z x} & k_{z y} & k_{z z}
\end{array}\right)\left(\begin{array}{l}
\partial T / \partial x \\
\partial T / \partial y \\
\partial T / \partial z
\end{array}\right) .
$$

Similarly, if the material is orthotropic with $z$ direction being TTT direction, Eq. (14) yields

$$
F_{\text {cond }, x}=k_{I P} \frac{\partial T}{\partial x}, \quad F_{\text {cond }, y}=k_{I P} \frac{\partial T}{\partial y}, \quad F_{\text {cond }, z}=k_{T T T} \frac{\partial T}{\partial z} .
$$

\section{Test Case Description}

In this work, a total of seven cases is performed using TACOT material, which is a theoretical light-weight ablative composite that has properties based as PICA. ${ }^{24,12}$ The sample geometry used in each case is an iso-Q shape, a geometry that is widely used in arc-jet experiments. The front surface curvature is described in Ref. 25.

Figure 1 illustrates the iso-Q sample geometry mesh as well as the location of virtual thermocouples. The idea of virtual thermocouples is to track the temperature history of selected points. The location of

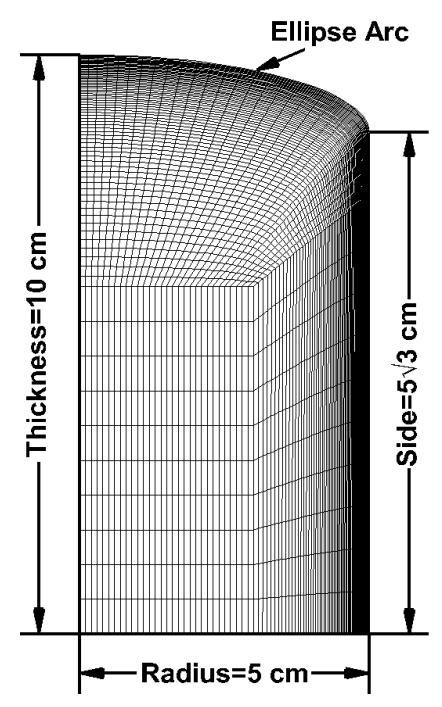

(a) Iso-Q $(30 \times 10+70 \times 40$ cells $)$

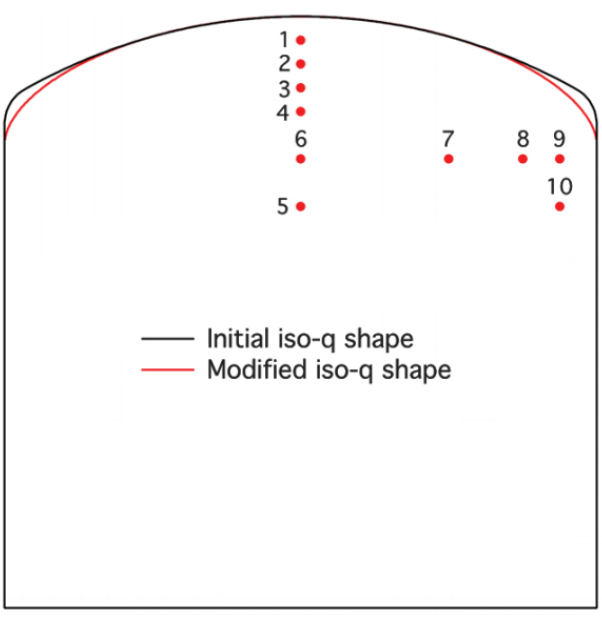

(b) Thermocouples location ${ }^{26}$

Figure 1. Geometry and thermocouples location of the iso-Q sample s5 $^{25}$

thermocouples are listed in Table 1.

Table 1. Coordinates of thermocouples

\begin{tabular}{lclc}
\hline \hline TC\# & Coordinate $(\mathrm{m})$ & TC\# & Coordinate $(\mathrm{m})$ \\
1 & $(0,0,-3.81 \mathrm{e}-3)$ & 6 & $(0,0,-2.286 \mathrm{e}-2)$ \\
2 & $(0,0,-7.62 \mathrm{e}-3)$ & 7 & $(2.54 \mathrm{e}-2,0,-2.286 \mathrm{e}-2)$ \\
3 & $(0,0,-1.143 \mathrm{e}-2)$ & 8 & $(3.81 \mathrm{e}-2,0,-2.286 \mathrm{e}-2)$ \\
4 & $(0,0,-1.524 \mathrm{e}-2)$ & 9 & $(4.445 \mathrm{e}-2,0,-2.286 \mathrm{e}-2)$ \\
5 & $(0,0,-3.048 \mathrm{e}-2)$ & 10 & $(4.445 \mathrm{e}-2,0,-3.048-2)$ \\
\hline
\end{tabular}

Since the objective of this work is to solely investigate the orthotropic material model, the boundary conditions and initial settings of each case are set to be identical. Figure 2 shows the boundary conditions 


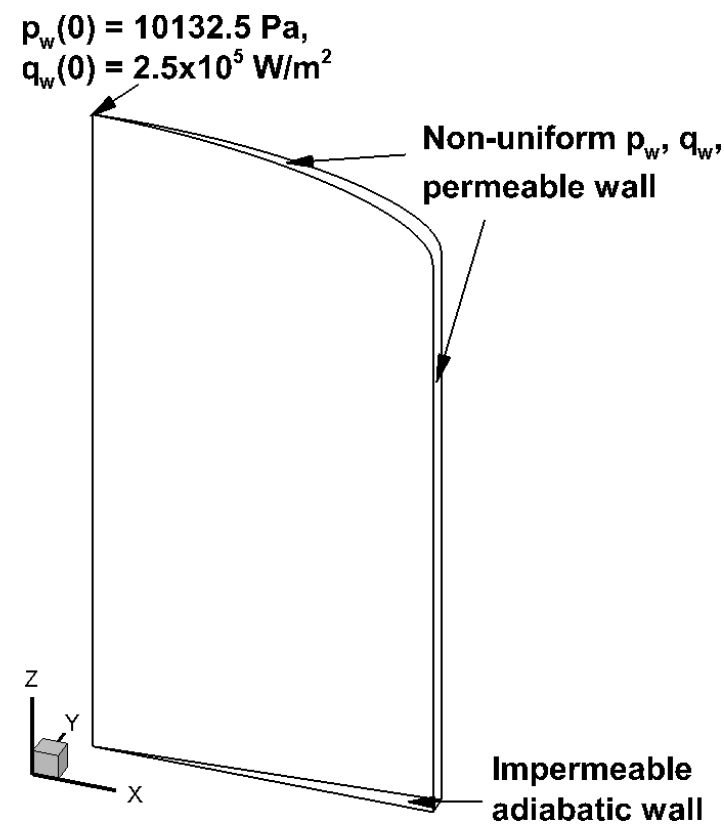

Figure 2. Illustration of boundary conditions and computational geometry

applied. The heat flux and pressure on the surface are non-uniform, the profiles of which are given in Fig. 3(a). The ramping profiles for both heat flux and pressure boundary condition are presented in Fig. 3(b). Note that the surface heat flux is directly applied as the boundary condition, that neither hot-wall nor blowing correction is used. The description of each test case is presented in the following.

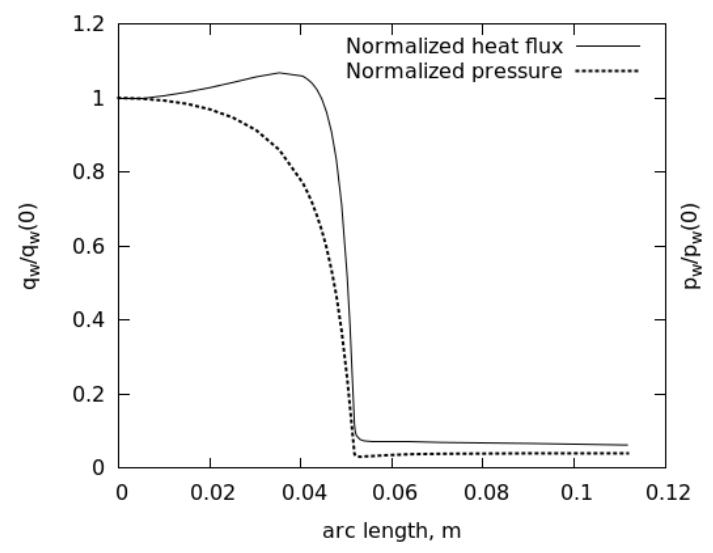

(a) Non-uniform Distribution

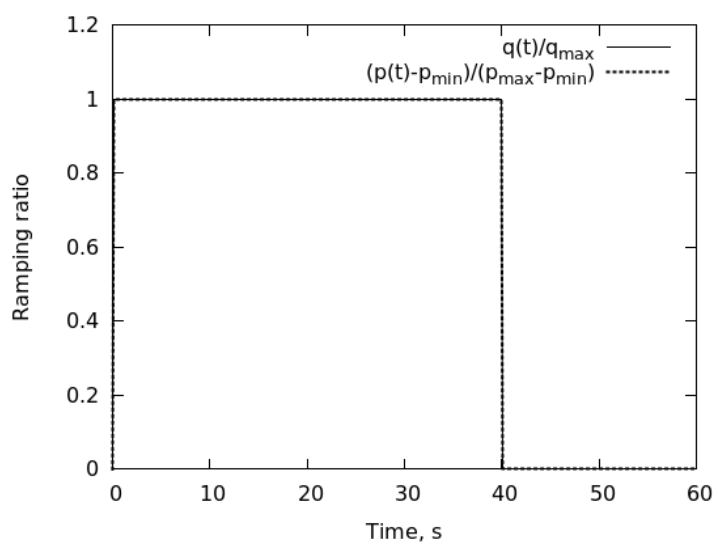

(b) Ramping over time

Figure 3. Pressure and heat flux boundary condition

- First case: the control test case, in which material properties are all isotropic. In the rest of the cases, orthotropic properties are used. In this work, the two orthotropic directions: in-plane orientation and through-the-thickness direction, are corresponding to x-y plane and z-direction, respectively.

- Second case: the permeability in IP direction is assumed to be twice as large as in TTT direction; the thermal conductivity is isotropic.

- Third case: the permeability in IP direction is assumed to be three times as in TTT direction; the thermal conductivity is isotropic.

- Fourth case: the permeability in IP direction is assumed to be half of the value in TTT direction; the thermal conductivity is isotropic. 
- Fifth case: the permeability is isotropic but the thermal conductivity in IP direction is assumed to be two times as in TTT direction.

- Sixth case: both the permeability and thermal conductivity in IP direction is assumed to be two times as in TTT direction.

- Seventh case: both the permeability and thermal conductivity in IP direction is assumed to be half of the value in TTT direction.

\section{Results and Discussion}

\section{V.A. Pyrolysis gas transport}

The numerical results of pyrolysis gas transport are presented in Figs. 4 to 10, for case 1 to case 7, respectively. In these plots, the contour $\left|\dot{m}^{\prime \prime}\right|$ represents the local momentum of pyrolysis gas, which is given as $\left|\dot{m}^{\prime \prime}\right|=$ $\phi \rho_{g} \sqrt{u^{2}+v^{2}+w^{2}}$. It is seen from Figs. 4 to 6 that, when permeability is greater in IP direction, the streamlines lean towards the horizontal IP direction, especially in the char layer; the shoulder point blowing rate is also increased. Then, in Fig. 7, the permeability is smaller in the IP direction and the streamlines lean towards the TTT direction. These effects are due to the fact that high permeability in one direction allows the gas to transport easier in that direction.

Comparing Fig. 4 with Fig. 8, it can be seen that the streamlines are very similar, if not identical. This suggests that the change of thermal conductivity has little influence on the gas flow direction. Notice that when comparing Fig. 4(a) with Fig. 8(a), it is clear to see the gas momentum right below the decomposition zone is slightly enhanced. This is probably caused by the greater thermal conductivity in the IP direction, which enhances the side wall heating and thus, raises the centerline temperature and enhances the pyrolysis gas generation.

When both orthotropic models are used, the material responses are the combination of each model. As expected, the streamlines in Fig. 9 are very close to the ones in Fig. 5, where they have the same permeability matrix. Because the permeability model dominates the pyrolysis gas flow direction. Similarly, Fig. 10 and Fig. 7 are quite close for the same reason. On the other hand, the orthotropic thermal conductivity has tiny effect on the gas momentum contour, which is due to the same analysis for case 5 .

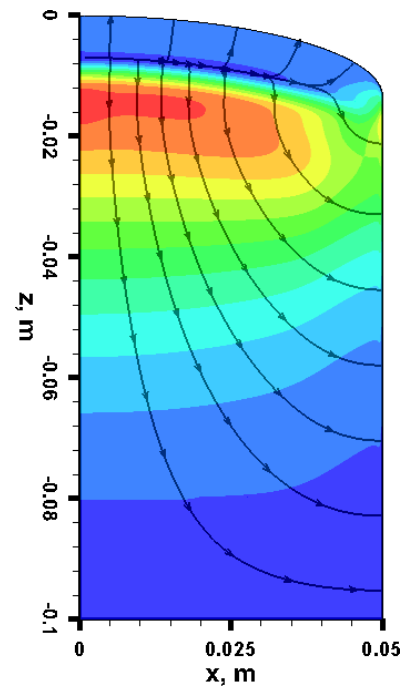

(a) $20 \mathrm{sec}$

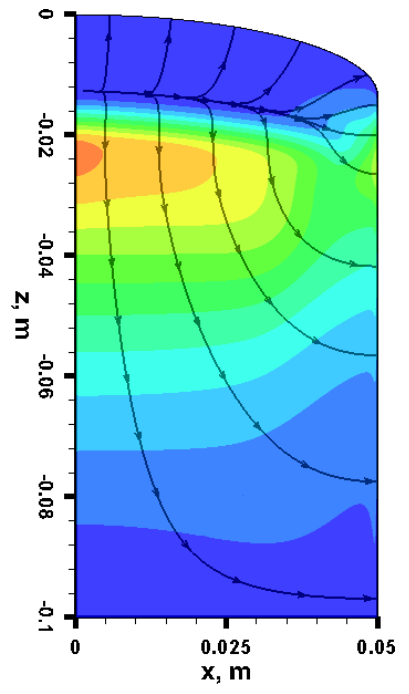

(b) $40 \mathrm{sec}$

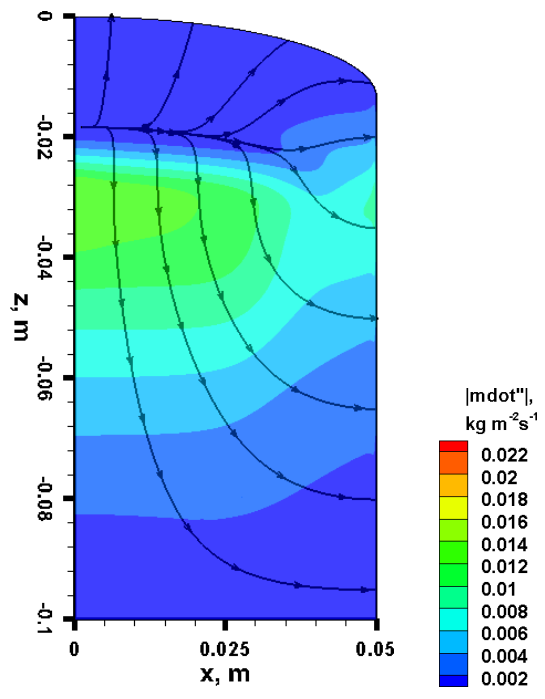

(c) $60 \mathrm{sec}$

Figure 4. Case 1: Isotropic permeability

\section{V.B. Thermocouple plots}

The temperature time-series on 10 thermocouple are presented in Figs. 11 to 20. The first case in which isotropic properties are used, is plotted using a solid line, while the others are dotted with symbols. Note 


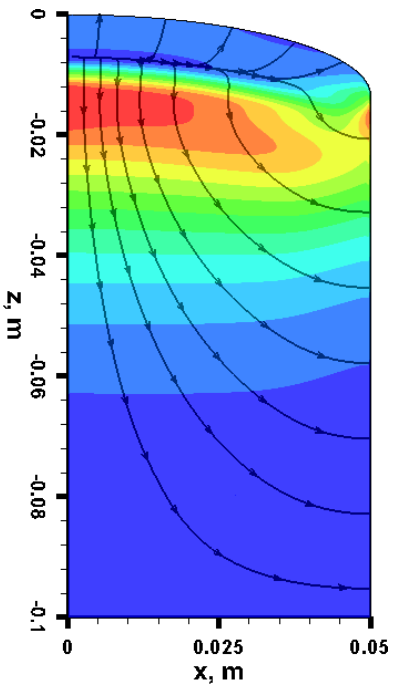

(a) $20 \mathrm{sec}$

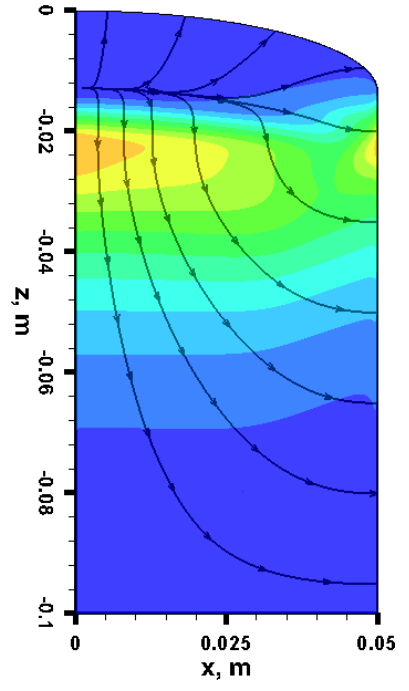

(b) $40 \mathrm{sec}$

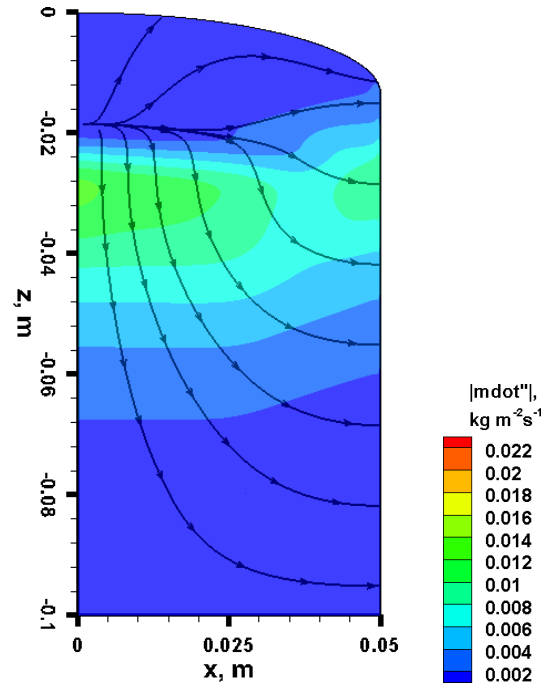

(c) $60 \mathrm{sec}$

Figure 5. Case 2: Orthotropic permeability: $K_{\mathrm{IP}} / K_{\mathrm{TTT}}=2$

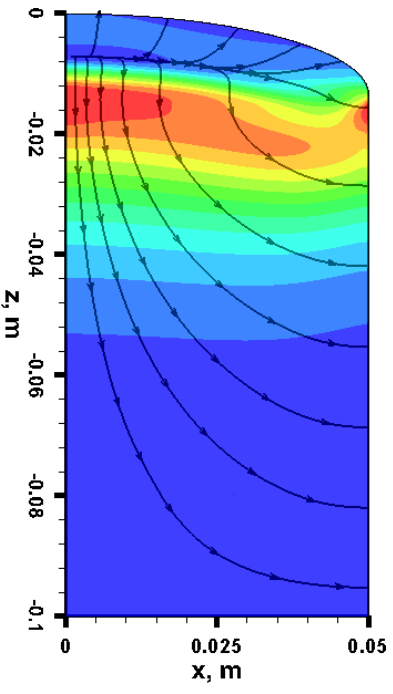

(a) $20 \mathrm{sec}$

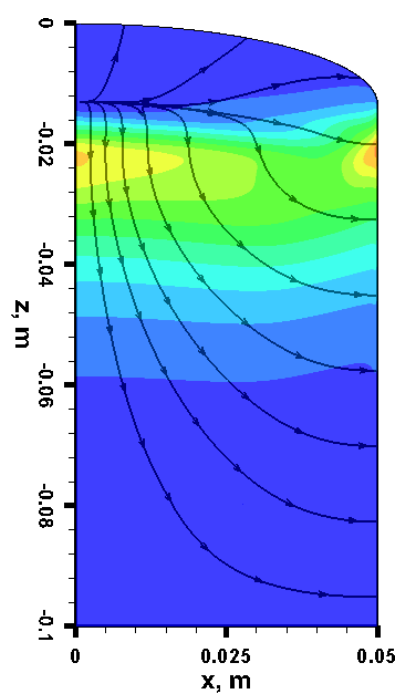

(b) $40 \mathrm{sec}$

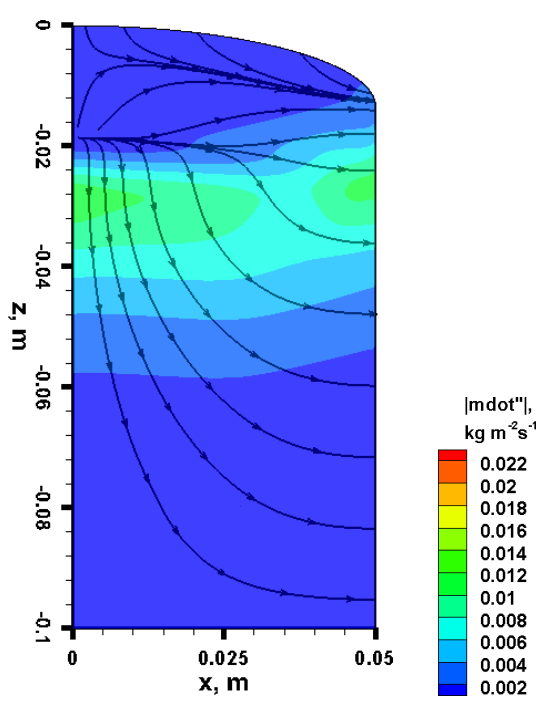

(c) $60 \mathrm{sec}$

Figure 6. Case 3: Orthotropic permeability: $K_{\mathrm{IP}} / K_{\mathrm{TTT}}=3$ 


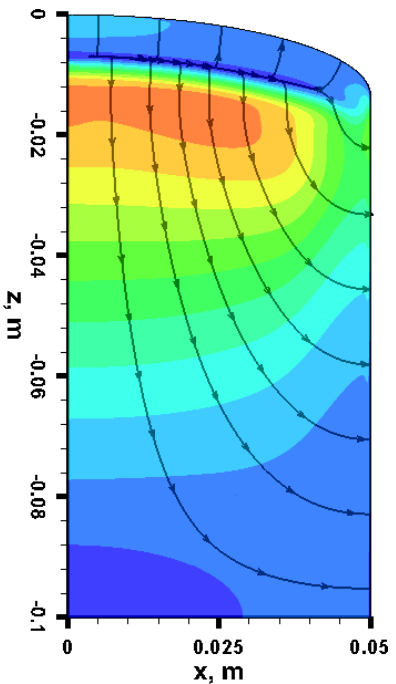

(a) $20 \mathrm{sec}$

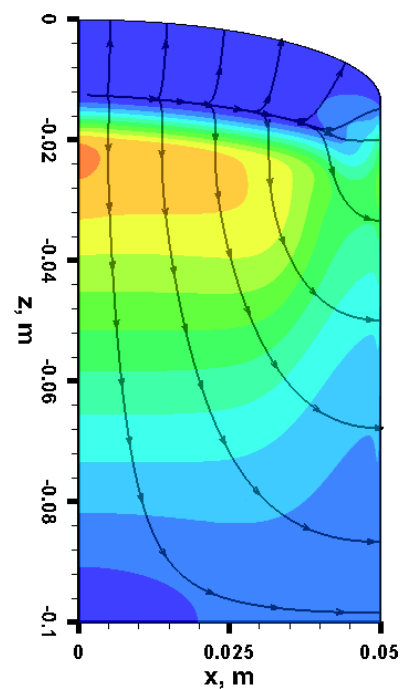

(b) $40 \mathrm{sec}$

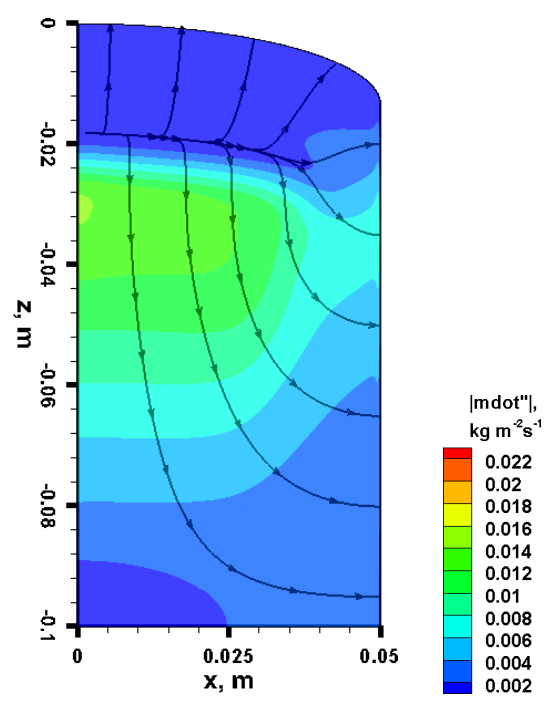

(c) $60 \mathrm{sec}$

Figure 7. Case 4: Orthotropic permeability: $K_{\mathrm{IP}} / K_{\mathrm{TTT}}=0.5$

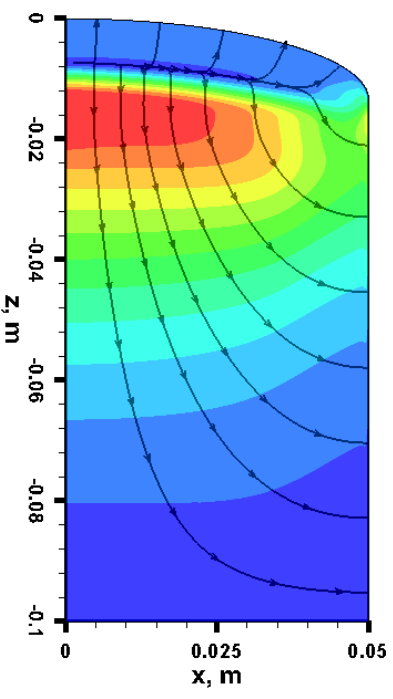

(a) $20 \mathrm{sec}$

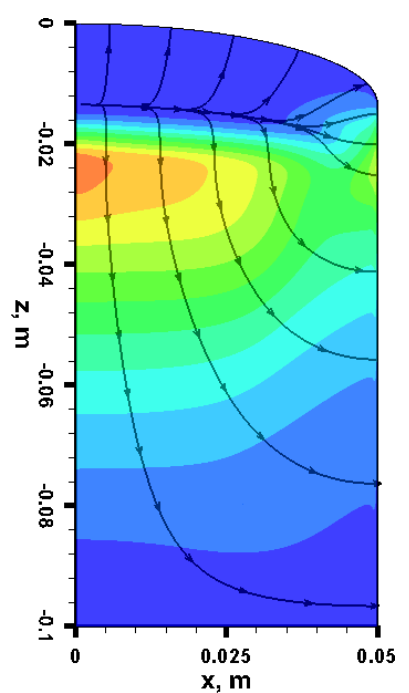

(b) $40 \mathrm{sec}$

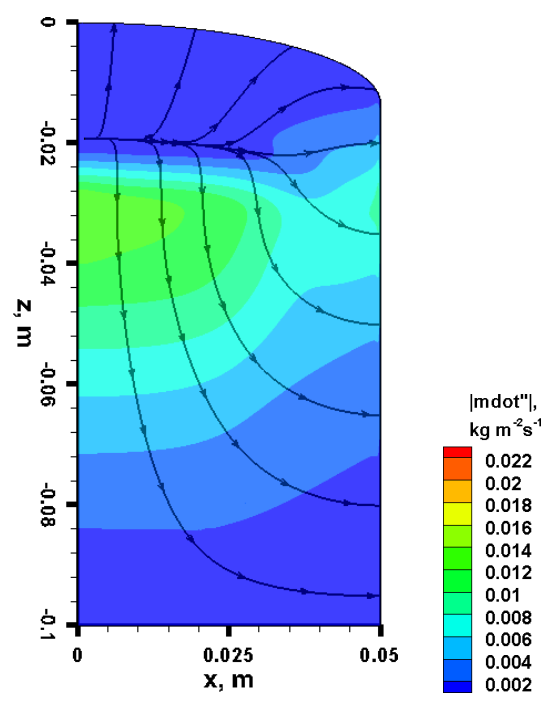

(c) $60 \mathrm{sec}$

Figure 8. Case 5: Orthotropic heat conductivity: $k_{\mathrm{IP}} / k_{\mathrm{TTT}}=2$ 


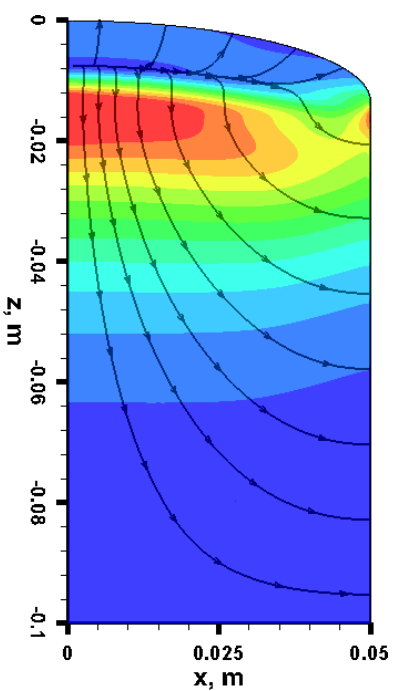

(a) $20 \mathrm{sec}$

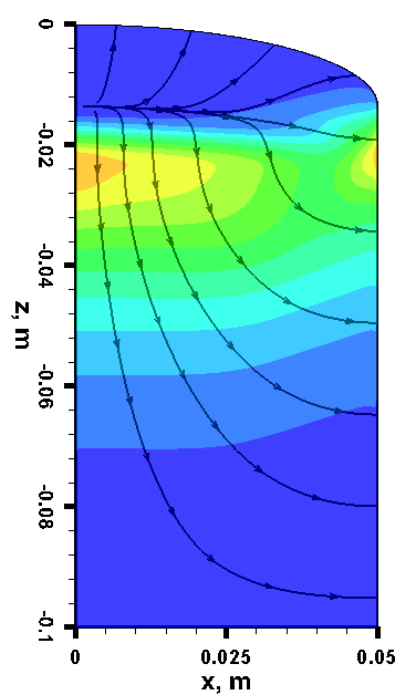

(b) $40 \mathrm{sec}$

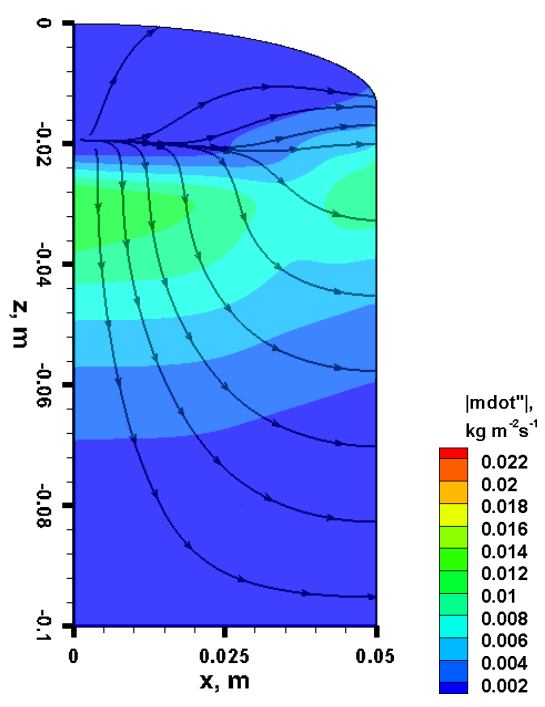

(c) $60 \mathrm{sec}$

Figure 9. Case 6: Orthotropic permeability and heat conductivity: $K_{\mathrm{IP}} / K_{\mathrm{TTT}}=k_{\mathrm{IP}} / k_{\mathrm{TTT}}=2$

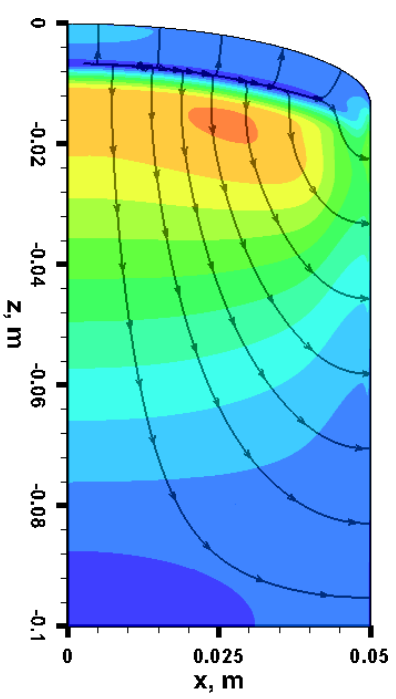

(a) $20 \mathrm{sec}$

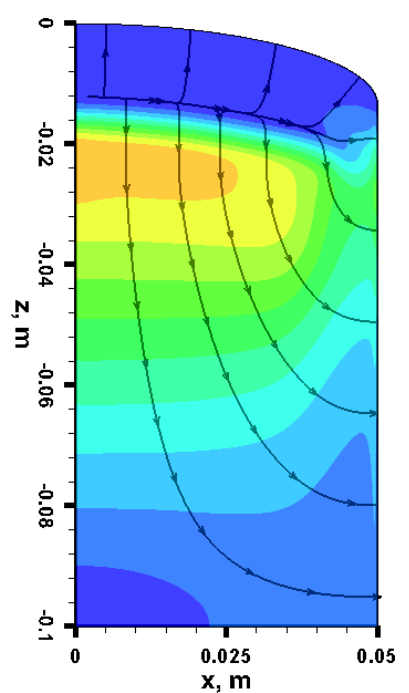

(b) $40 \mathrm{sec}$

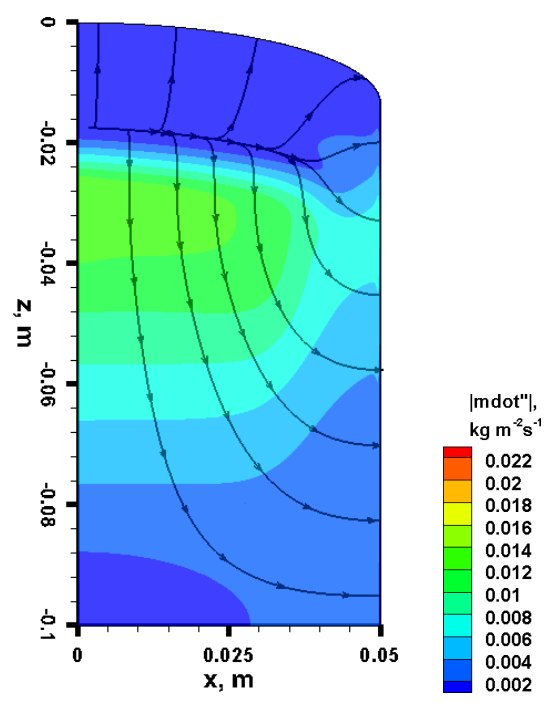

(c) $60 \mathrm{sec}$

Figure 10. Case 7: Orthotropic permeability: $K_{\text {IP }} / K_{\text {TTT }}=k_{\text {IP }} / k_{\text {TTT }}=0.5$ 
that, the first six thermocouples are located on the centerline of the iso-Q sample. The temperature profiles on these points confirms the side wall heating effects, since the temperature rises when the in-plane thermal conductivity is doubled, which enhances the horizontal heat transfer. It is also interesting to see that permeability (or gas transport) also alters the thermal response. When the permeability on IP direction is increased, the centerline temperature is also increased. This is likely due to the fact that when horizontal gas transport is encouraged, more gas is pulled downward from pyrolysis zone and exits through the side-wall; the hot gas going down further heats up the centerline material.

For thermocouples 7 to 10, the temperature profile shows different results. For high IP thermal conductivity, the temperature is higher than the isotropic case at the beginning, then it drops below the solid line at around 40 seconds (the time when heat is removed). This can be explained by the fact that when the side-wall heat flux is applied, the temperature rises faster due to the higher thermal conductivity. When heat is removed, the temperature also drops faster. On the other hand, when IP permeability is increased, the temperature on these thermocouples is lower than the isotropic case. This is due to the fact that the gas within the material is relatively cold compared to the heated side wall. When the gas is transported horizontally towards the side, the cooler gas brings down the temperature at these thermocouple locations.

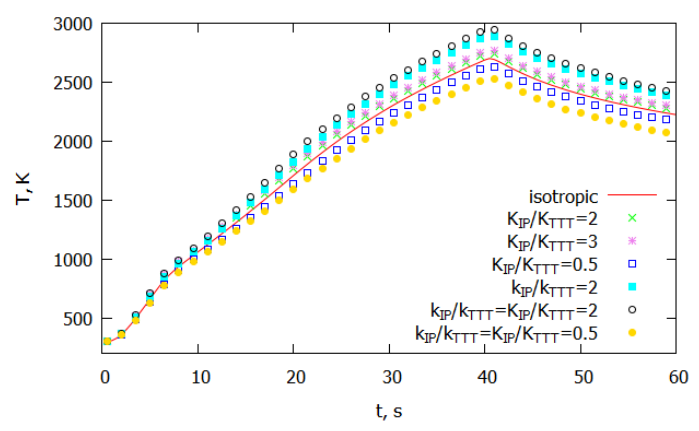

Figure 11. Thermocouple 1

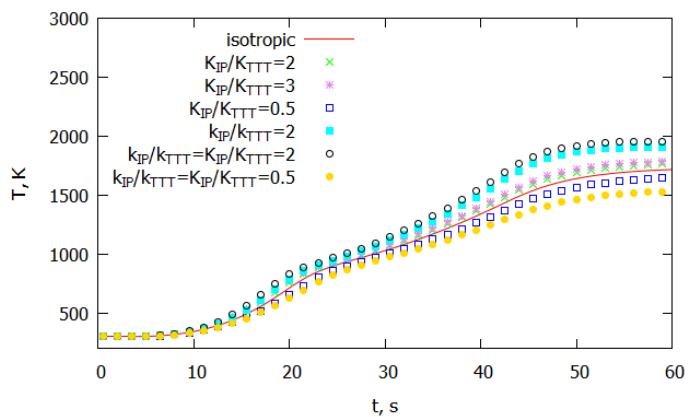

Figure 13. Thermocouple 3

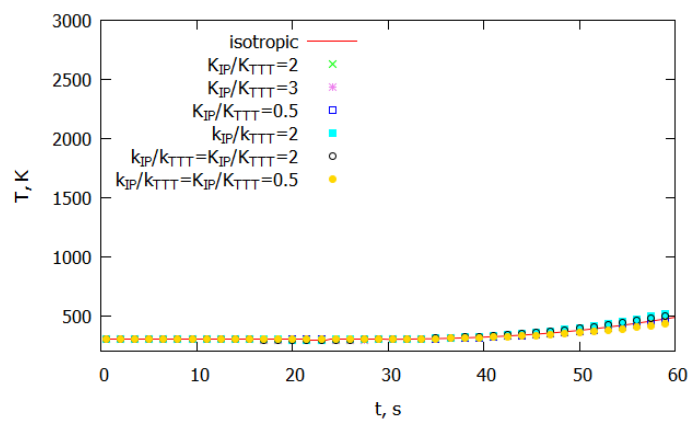

Figure 15. Thermocouple 5

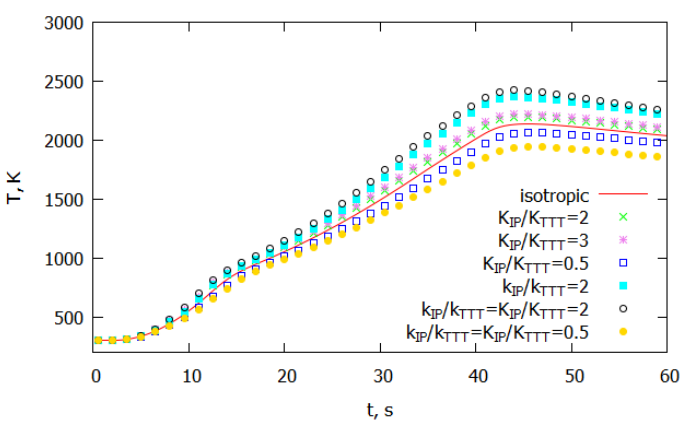

Figure 12. Thermocouple 2

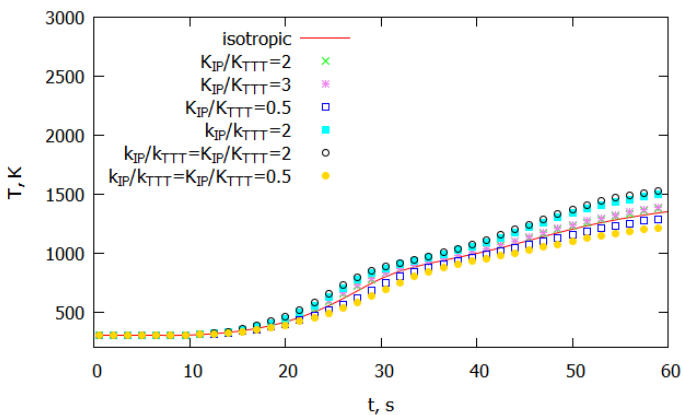

Figure 14. Thermocouple 4

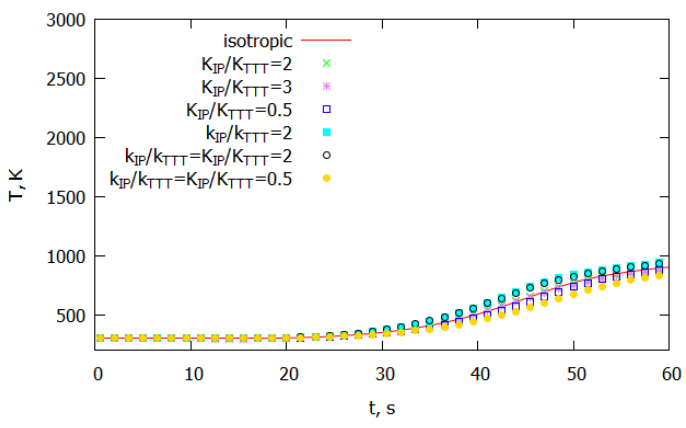

Figure 16. Thermocouple 6 


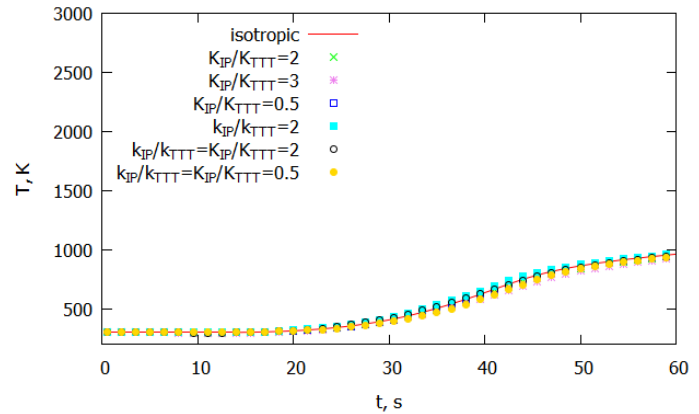

Figure 17. Thermocouple 7

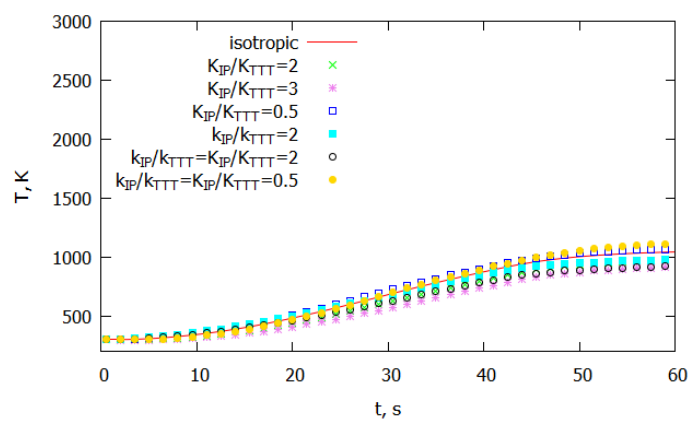

Figure 19. Thermocouple 9

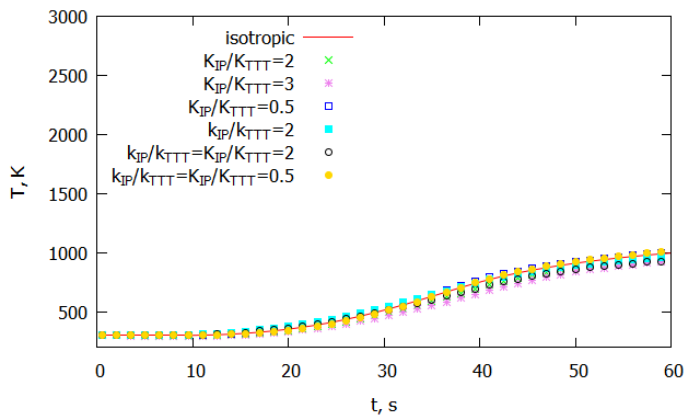

Figure 18. Thermocouple 8

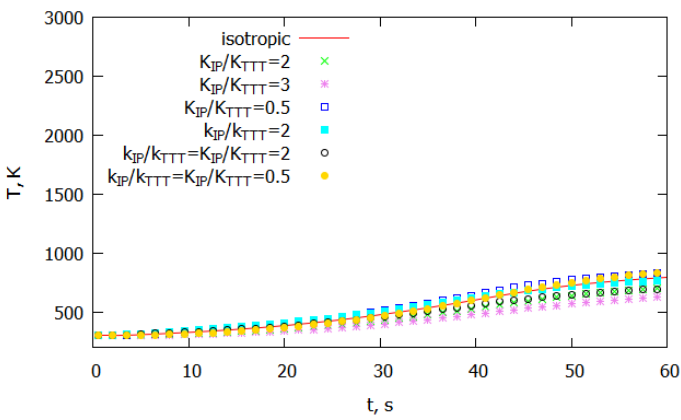

Figure 20. Thermocouple 10

\section{Conclusions}

As a conclusion, an orthotropic material properties model was numerically studied by performing a series of 3D simulations on an iso-Q shaped model. As expected, the orthotropic model affected the inner thermal response and the pyrolysis gas flow pattern greatly. In particular, the orthotropic permeability enhanced the pyrolysis gas flow in the direction that has higher permeability. Using this knowledge, the gas flow within the material and the blowing direction can be manipulated by altering the orientation angle of the material to obtain the desired thermal or blowing performance.

Orthotropic permeability also altered the thermal response slightly. It was shown that if IP direction permeability was higher, the centerline temperature increased, and the temperature near shoulder region decreased. On the other hand, the influence of orthotropic thermal conductivity on pyrolysis gas flow was small. However, it greatly affected the thermal response (temperature) of the material. When the thermal conductivity in IP direction was higher, the centerline temperature was increased, which proved the hypothesis of side-wall heating effect.

In summary, the results of this study have 1) demonstrated the complex effects of orthotropic material properties, 2) shown the effects of pyrolysis gas flow on thermal response, 3) shown the importance of using orthotropic model, and 4) validated the orthotropic properties model using the MR module of KATS.

\section{Acknowledgments}

Financial support for this work was provided by NASA Kentucky EPSCoR Award NNX10AV39A, and NASA award NNX13AN04A. The author would like to thank Huaibao Zhang and Dr. Francesco Panerai at the University of Kentucky, Tom van Eekelen at LMS-SAMTECH, Dr. Nagi N. Mansour at NASA Ames Research Center, and Dr. Jean Lachaud at University of California, Santa Cruz for several useful discussions.

\section{References}

\footnotetext{
${ }^{1}$ Bose, D., Olson, M., Laub, B., White, T., Feldman, J., Santos, J., Mahzari, M., MacLean, M., Dufrene, A., and Holden, M., "Initial Assessment of Mars Science Laboratory Heatshield Instrumentation and Flight Data," 51st AIAA Aerospace
} 
Sciences Meeting, AIAA Paper 2013-908, Grapevine, TX, January 7-10 2013.

doi:doi:10.2514/6.2013-908

${ }^{2}$ Vellinga, J., Craig, C. L., Gellis, R. T., Rasback, C. E., Rogers, J. J., Thorton, M. G., Willcockson, W. H., Brownlee, D. E., and Atkins, K. L., "Enviromental Design Considerations for Stardust," Technical Paper 972278, Society of Automotive Engineers, July 1997.

${ }^{3}$ Mansour, N. N., Panerai, F., Martin, A., Parkinson, D. Y., MacDowell, A. A., Haboub, A., Sandstrom, T. A., Fast, T., Vignoles, G. L., and Lachaud, J., "A New Approach To Light-Weight Ablators Analysis: From Micro-Tomography Measurements to Statistical Analysis and Modeling," 44th AIAA Thermophysics Conference, AIAA, San Diego, CA, June 24-27 2013. doi: $10.2514 / 6.2013-2768$

${ }^{4}$ Weng, H. and Martin, A., "Multi-dimensional Modeling of Pyrolysis Gas Transport Inside Charring Ablative Materials," Journal of Thermophysics and Heat Transfer, Accepted on March 122014.

${ }^{5}$ Alkandry, H., Boyd, I. D., and Martin, A., "Coupled Flow Field Simulations of Charring Ablators with Nonequilibrium Surface Chemistry," 44th AIAA Thermophysics Conference, AIAA, San Diego, California, June 24-27 2013. doi:10.2514/6.2013-2634

${ }^{6}$ van Eekelen, T., Bouilly, J.-M., Hudrisier, S., Dupillier, J.-M., and Aspa, Y., "Design and numerical modelling of charring material ablators for re-entry applications," 6th European Workshop on Thermal Protection Systems and Hot Structures, European Space Agency - WPP-319, University Stuttgart, Germany, November 21-25 2009.

${ }^{7}$ Amar, A. J., Calvert, N. D., and Kirk, B. S., "Development and Verification of the Charring Ablating Thermal Protection Implicit System Solver," 49th AIAA Aerospace Sciences Meeting and Exhibit, AIAA paper 2011-144, Orlando, FL, January 4-7 2011.

doi:10.2514/6.2011-144

${ }^{8}$ Ewing, M. E. and Richardson, D. E., "Phenomena and material property requirements for a combined structural and thermal ablation model," 4th AFOSR/SNL/NASA Ablation Workshop, Albuquerque, NM, March 2011.

${ }^{9}$ Lachaud, J. and Mansour, N. N., "A pyrolysis and ablation toolbox based on OpenFOAM - with application to material response under high-enthalpy environments," 5th OpenFOAM Workshop, Chalmers University, Gothenburg, Sweden, June 2010.

${ }^{10}$ Hirata, N., Nozawa, S., Takahashi, Y., Kihara, H., and ichi Abe, K., "Numerical study of pyrolysis gas flow and heat transfer inside an ablator," Computational Thermal Sciences, Vol. 4, No. 3, 2012, pp. 225-242.

doi:10.1615/ComputThermalScien.2012004762

${ }^{11}$ Marschall, J. and Cox, M. E., "Gas Permeability of Lightweight Ceramic Ablators," Journal of Thermophysics and Heat Transfer, Vol. 13, No. 3, 1999, pp. 383-386.

doi: $10.2514 / 2.6451$

${ }^{12}$ Tran, H. K., Johnson, C. E., Rasky, D. J., Hui, F. C. L., Hsu, M.-T., Chen, T., Chen, Y. K., Paragas, D., and Kobayashi, L., "Phenolic impregnated carbon ablators (PICA) as thermal protection systems for discovery missions," Technical Report 110440, NASA Technical Memorandum, 1997.

${ }^{13}$ Tran, H. K., Johnson, C., Rasky, D., Hui, F., and Hsu, M.-T., "Silicone Impregnated Reusable Ceramic Ablators for Mars Follow-On Missions," AIAA paper 96-1819, June 1996.

${ }^{14}$ Marschall, J. and Milos, F. S., "Gas permeability of rigid fibrous refractory insulations," Journal of Thermophysics and Heat Transfer, Vol. 12, No. 4, 1998, pp. 528-535.

doi:10.2514/2.6451

${ }^{15}$ Moyer, C. B. and Rindal, R. A., "AN ANALYSIS OF THE COUPLED CHEMICALLY REACTING BOUNDARY LAYER AND CHARRING ABLATOR PART I," Contractor report, NASA, 1968.

${ }^{16}$ Chen, Y.-K. and Milos, F. S., "Ablation and Thermal Response Program for Spacecraft Heatshield Analysis," Journal of Spacecraft and Rockets, Vol. 36, No. 3, May-June 1999, pp. 475-483.

doi:10.2514/2.3469

${ }^{17}$ Martin, A. and Boyd, I. D., "Non-Darcian Behavior of Pyrolysis Gas in a Thermal Protection System," Journal of Thermophysics and Heat Transfer, Vol. 24, No. 1, January-March 2010, pp. 60-68.

doi:10.2514/1.44103

${ }^{18}$ Weng, H., Zhang, H., Khan, O. U., and Martin, A., "Multi-dimensional modeling of charring ablators," 43rd AIAA Thermophysics Conference, AIAA Paper 2012-2748, New Orlean, LA, June 25-28 2012. doi:10.2514/6.2012-2748

${ }^{19}$ Zhang, H., Martin, A., and McDonough, J. M., "Parallel Efficiency of the FreeCFD Code for Hypersonic Flows with Chemistry," 24th International Conference on Parallel Computational Fluid Dynamics, Atlanta, GA, May 21-25 2012.

${ }^{20}$ Schloegel, K., Karypis, G., and Kumar., V., "Parallel Multilevel Algorithms for Multi-Constraint Graph Partitioning," Euro-Par, 2000, pp. 296-310.

${ }^{21}$ Liou, M.-S., "A sequel to AUSM, Part II: AUSM+-up for all speeds," Journal of Computational Physics, Vol. 214, No. 1, 2006, pp. $137-170$.

doi:10.1016/j.jcp.2005.09.020

${ }^{22}$ Balay, S., Brown, J., Buschelman, K., Gropp, W.-D., Kaushik, D., Knepley, M.-G., McInnes, L.-C., Smith, B.-F., and Zhang, H., "PETSc Web page http://www.mcs.anl.gov/petsc," 2013.

${ }^{23}$ Darcy, H., "Les Fontaines Publiques de la Ville de Dijon," Dalmont, Paris, France, 1856.

${ }^{24}$ Lachaud, J., Martin, A., Cozmuta, I., and Laub, B., "Ablation test-case series \#1," 4th AFOSR/SNL/NASA Ablation Workshop, Albuquerque, NM, March 1-3 2010.

${ }^{25}$ van Eekelen, T., Martin, A., Lachaud, J., and Bianchi, D., "Ablation test-case series \#3: Numerical simulation of ablative-material response: code and model comparisons," 6th Ablation Workshop, Urbana Champaign, IL, February 2014. 
${ }^{26}$ Milos, F. S. and Chen, Y.-K., "Two-Dimensional Ablation, Thermal Response, and Sizing Program for Pyrolyzing Ablators," Journal of Spacecraft and Rockets, Vol. 46, No. 6, November-December 2009, pp. 1089-1099. doi: $10.2514 / 1.36575$ 